Bull. Mater. Sci., Vol. 14, No. 1, February 1991, pp. 77-85. (C) Printed in India.

\title{
Curing of visible light-activated dental restorative composites
}

\author{
S N PAL, R VOWLES $\dagger$ and D F WILLIAMS* $†$ \\ Division of Polymer Technology, Sree Chitra Tirunal Institute for Medical Sciences and \\ Technology, Trivandrum 695012 , India \\ †Institute of Medical and Dental Bioengineering, University of Liverpool, Liverpool L69 \\ 3BX, UK \\ MS received 1 January 1991
}

\begin{abstract}
FTIR spectroscopy and microhardness measurements were employed to follow the degree of curing of visible light activated dental composites. The observed dependence of curing on grade and shade of the materials, exposure time and depth from the light exposed surface have been discussed. Immediately after curing, it was found that direct correlation of microhardness values with that of double bond conversion estimated by FTIR technique could not be established.
\end{abstract}

Keywords. Dental composites; bis-GMA; microhardness; FTIR spectroscopy; depth of cure.

\section{Introduction}

Ceramic-filled resin composites are widely used in restorative, orthodontic and cosmetic dentistry. Visible light-cured composite systems are preferred over chemical curing systems due to their ease of manipulation, extended working time and lesser porosity in the set material. (Pollack et al 1982; Reinhardt et al 1982; Newman et al 1983). The degree of polymerization in the polymeric phase clearly has a role in determining the ultimate physical and mechanical properties of the cured material. Residual methacrylate groups may be responsible for reduced hardness, wear resistance, strength and colour stability in the Bis-GMA-based dental restorative resin (Asmussen 1982; Ferracane 1982, 1983; Wu 1983). Residual double bonds in polymeric materials are also known to make them less resistant to degradation (Ruyter and Gyorosi 1976).

The degree of cure at different distances from the surface of these photopolymerisable composite materials has been assessed by studying hardness at different depths from the light exposed curing surface (Ruyter et al 1981; Tirtha et al 1982; Swartz et al 1983; Abdalla et al 1985). Studies have also been made to estimate the degree of polymerization by quantitatively measuring remaining unsaturated groups by Ir spectroscopy techniques (Ruyter and Gyorosi 1976; Ferracane and Greener 1984). The present work was aimed at studying the curing behaviour at different depths from the light-exposed surface by both the methods and investigating the possibility of correlating microhardness values with percentage double-bond conversion. Earlier studies have mostly been on aged samples and since failure of many composites may have their origin in the behaviour over the first few hours or days of application, the present study was designed to follow microhardness development and double-bond conversion immediately after curing.

*For correspondence 


\section{Materials and methods}

Composite resins used for the study are listed in table 1 . All the resins were of the visible light curing type and consisted of three shades of the material Occlusin and one of the material Heliomolar. A visible light source (Luxor, ICI) was used for curing for periods ranging from 10 to 60 seconds.

\subsection{Microhardness}

Microhardness measurements were performed using a Zeiss MHP microhardness tester. The diamond indentor was a square-based pyramid suitable for Vickers hardness measurement. A load of 100 grams was used for all the tests. Samples $(6 \mathrm{~mm} \times 4 \mathrm{~mm} \times 2 \mathrm{~mm}$ ) were made using a stainless steel mould (figure 1) with a removable and highly polished stainless steel lid fixed over the top of the channel.

The mould was placed on its side over a glass slide and composite resin was packed into the mould from the open end of the channel. The open end was then covered with another glass slide and the material was packed with finger pressure on the glass sides and was cured from one end with visible light for the specified duration. The delivery end of the light source was kept in contact with the glass slides at the time of curing. The glass slides were then removed and the samples, without removing from the mould, were stored in a light-tight enclosure until testing, which was completed within 1 hour of curing. During testing, the channel lids were removed and moulds containing the cured samples were mounted in a holder on the microscope stage. The moulds act as support for the sample and help in mounting on to the stage. After examining the sample with a microscope, the indentor was moved into position and the microscope stage was raised steadily until the load was applied by the indentor on the sample surface and held for 15 seconds. Differential interference contrast microscopy was used to determine the dimensions of the indentation and the Vickers hardness value was calculated using the formula

$$
H_{v}=(1854.4 \times P) / d^{\Lambda} 2,
$$

where $P$ is the load (in grams) and $d$ the length of diagonal (in $\mu \mathrm{m}$ ). Microhardness was measured at different depths from the irradiated surface. For each depth at least 5 measurements were taken across a $2.5 \mathrm{~mm}$ wide area in the centre of the specimen.

\subsection{Double-bond conversion}

The degree of double-bond conversion was analysed by Fourier transform infrared

Table 1. List of composite resins used for the present study.

\begin{tabular}{lllc}
\hline Name & Code & Batch No & Manufacturer \\
\hline Occlusin-S & OCS & DA 361 TD & ICI \\
& & DA 361 (S) & ICI \\
Occlusin-DY & OCDY & 71 JAN 87 & ICI \\
Occlusin-LG & OCLG & AO 80 JAN 87 & ICI \\
Heliomolar-U & HLMU & 436901,636901 & Vivadent \\
& & & Liechtenstein \\
\hline
\end{tabular}




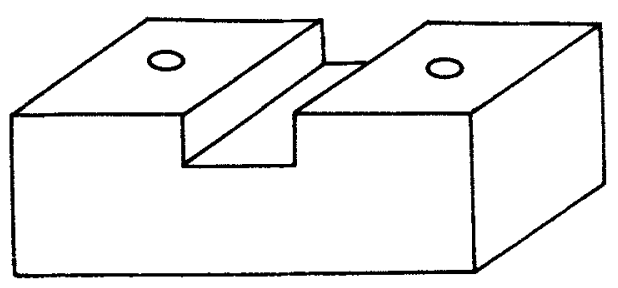

Figure 1. Mould used for microhardness tests.

spectrometer (FTIR, Nicolet 5DX) with ATR attachment. Samples were prepared in dental stone moulds (figure $2 \mathrm{a}$ ) with $5 \mathrm{~mm}$ deep cavities. These moulds were made from a two-piece press-fit and easily detachable PTFE mould (figure $2 \mathrm{~b}$ ). The composite resins were packed in the dental stone mould cavities and glass microscope slides were placed on top and pressed with finger pressure. Curing was performed for varying periods by visible light, the delivery end of which was kept in contact with glass slides. Immediately after curing the dental stone moulds containing the samples were sliced into four sections, each $1 \mathrm{~mm}$ thick; with the help of a fine diamond-edged cutting wheel run at low speed. Precautions were taken to avoid contamination. After marking for identification, the slices were stored in light-tight containers and used for recording of spectra within an hour. The four slices ranged from $0-1 \mathrm{~mm}, 1.4-2.4 \mathrm{~mm}, 2.8-3.8 \mathrm{~mm}$ and $4.2-5 \mathrm{~mm}$ in depth from the top curing surface (figure $2 \mathrm{c}$ ).

The rationale of the test method employed for determining the extent of doublebond conversion was suggested earlier (Ferracane and Greener 1984). Uncured resins were smeared on to KRS-5 crystal and cured slices, after breaking off the dental stone, were placed in the holder within the spectrometer. Spectra for 100 scans were recorded between 1750 and $1550 \mathrm{~cm}^{-1}$. The intensities of the $C=C$ absorbance peak at $1639 \mathrm{~cm}^{-1}$ and $C \ldots C$ reference peak at $1609 \mathrm{~cm}^{-1}$ were noted using a standard base line technique (Heigl et al 1947). The $C \ldots C$ peak at $1609 \mathrm{~cm}^{-1}$ originates from the aromatic ring of the Bis-GMA molecule and its intensity does not change during polymerization. The percentage of unreacted double bonds is expressed by (Ruyter and Svendsen 1978)

$$
\begin{aligned}
(\% C=C) & \frac{[\mathrm{abs}(C=C) / \mathrm{abs}(C \ldots C)] \text { polymer }}{[\mathrm{abs}(C=C) / \mathrm{abs}(C \ldots)] \text { monomer }} \times 100 \\
& \% \text { double bond converted }=100-(\% C=C) .
\end{aligned}
$$

\section{Results and discussion}

Microhardness results are shown in figures 3-7. All hardness values are lower than those recorded by us earlier on samples aged for 7 days. For example, surface hardness for OCS for $60 \mathrm{~s}$ cure time was found to be $75 \mathrm{~kg} \mathrm{~mm}^{-2}$ in our present study while in our earlier study a hardness value of $122 \mathrm{~kg} \mathrm{~mm}^{-2}$ was recorded after 7 days of ageing. Watts et al (1987) using Knoop hardness measurement, observed that initial hardness, measured immediately after curing, was almost invariably $<50 \%$ of the final value, measured at 1 month. This confirms the phenomena seen here. 


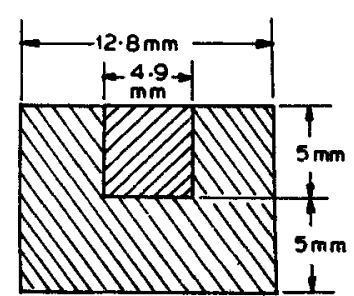

(a)

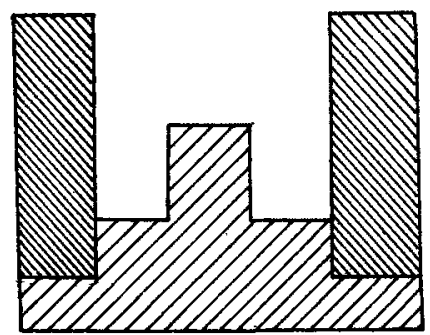

(b)

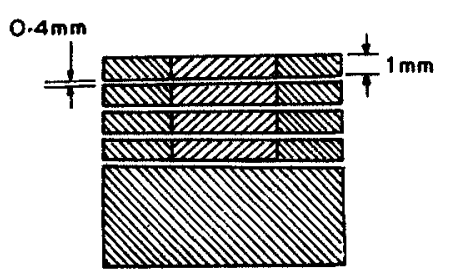

(c)

Figure 2. a. Dental stone mould for FTIR study. b. PTFE mould for casting dental stone. c. Slices cut at different locations of dental stone mould for FTIR study.

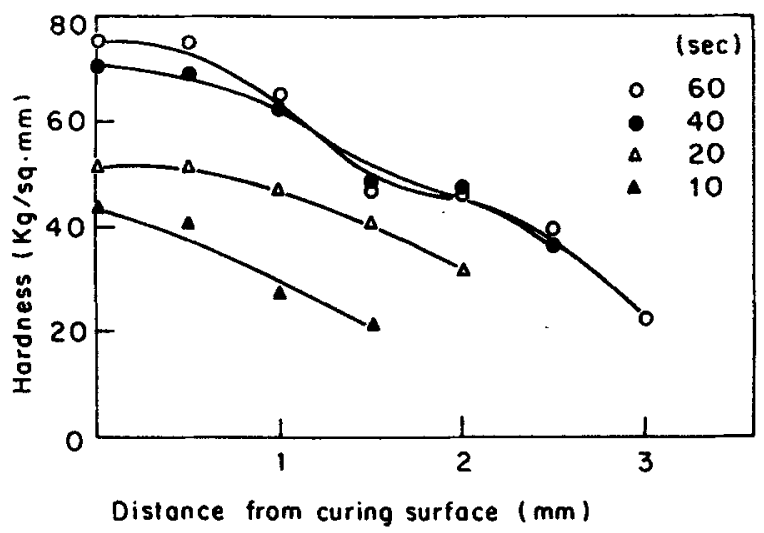

Figure 3. Microhardness for different curing times. Material: OCS.

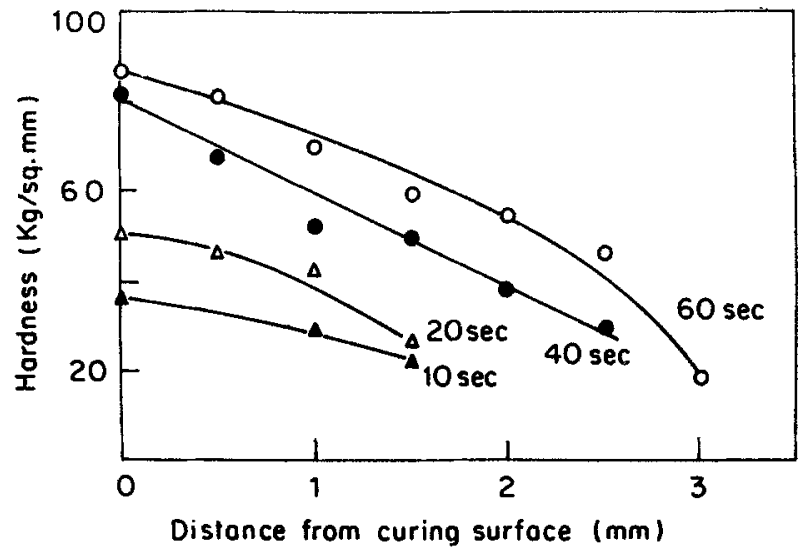

Figure 4. Microhardness for different curing times. Material: OCLC.

Hardness values generally fall with an increase in distance from the curing surface for all samples and all cure times. In an earlier study it was reported that the maximum hardness value is achieved at $0.5 \mathrm{~mm}$ to $1.0 \mathrm{~mm}$ below the irradiated surface and hardness at the irradiated surface itself is slightly lower (Onose et al 


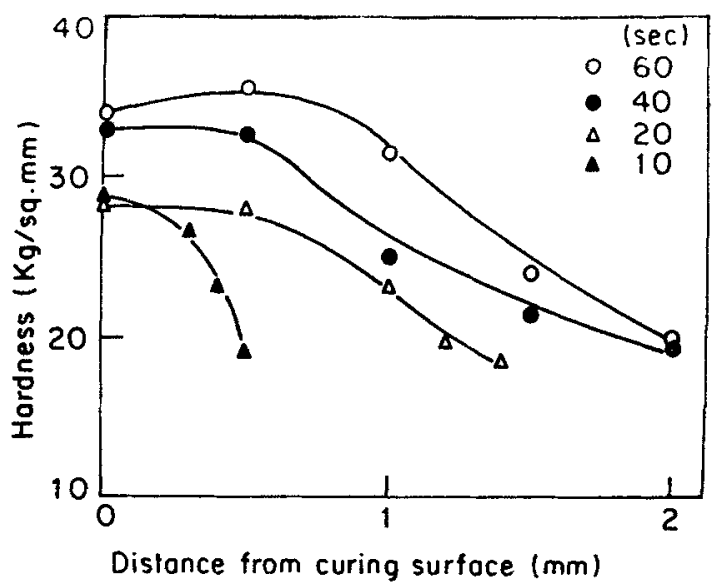

Figure 5. Microhardness for different curing times. Material: HLMU.

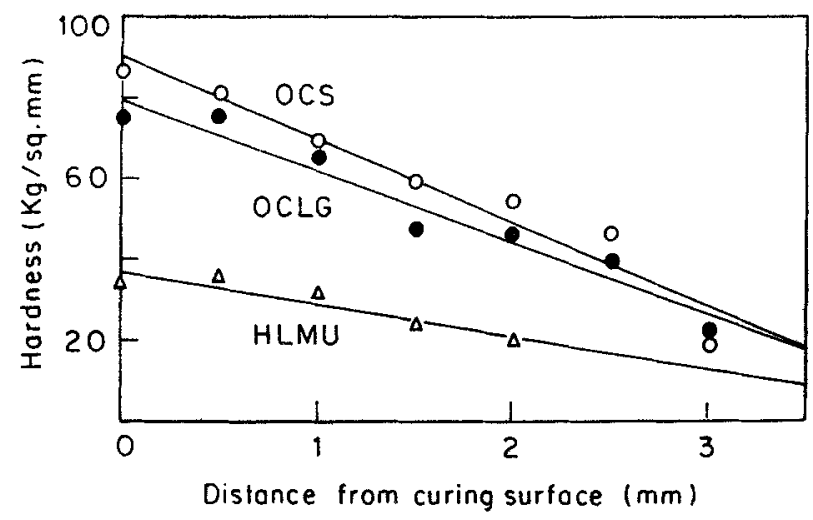

Figure 6. Comparative microhardness for different materials. Curing time: $60 \mathrm{~s}$.

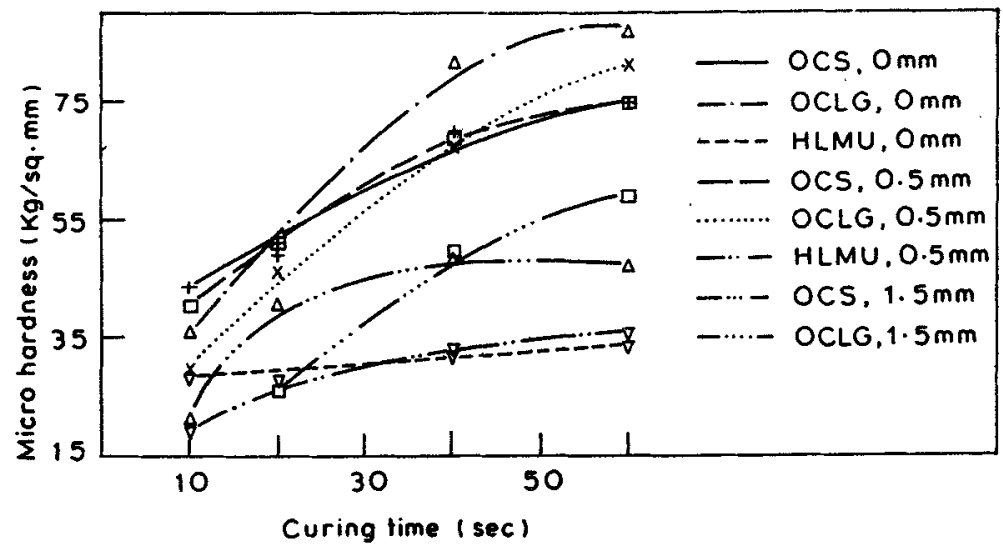

Figure 7. Microhardness for different materials at different depths from curing surface.

1985). This behaviour was explained by the retardation of polymerization on the surface due to the presence of oxygen. We, however, observed that the hardness 
which developed immediately after curing at $0.5 \mathrm{~mm}$ depth is similar to the hardness developed on the surface. At $1 \mathrm{~mm}$ depth there is a noticeable fall in hardness value and beyond $1 \mathrm{~mm}$ depth the fall in hardness value is rapid. The practical significance of this observation is that for cavities deeper than $1 \mathrm{~mm}$ and filled with visible light curing composites, adequate properties may not be developed in the filled material. In such cases it is advisable to place and cure the material incrementally.

The materials investigated develop different levels of hardness at the same distance from the irradiated surface under similar curing conditions. The surface hardness developed for all Occlusin grades are significantly higher than Heliomolar. For Occlusin OCS, hardness values for 60 and $\mathbf{4 0}$ seconds of curing are similar, but otherwise hardness values for all samples at any particular depth are higher with higher curing time of up to 60 seconds. A curing time of 20 seconds results in surface hardness significantly less than that obtained with a curing time of 40 seconds or more for the Occlusin samples. For HLMU the difference is not that pronounced, but for this material hardness for even $60 \mathrm{~s}$ curing is very low compared to OCS and OCLG. The implication of this observation is that curing for 20 seconds or less is inadequate for Occlusin grades investigated and even curing time of 60 seconds seem to be inadequate for HLMU. HLMU is more viscous than the other two materials investigated and lower viscosity of OCS and OCLG suggests better diffusion of reactive groups leading to a higher degree of polymerization and therefore higher hardness.

Double bond conversion results are shown in figures 8 and 9. Figure 8, referring to the first slice for different periods of irradiation, reveals that there are significant differences in conversion of double bonds for the three materials investigated. The much higher viscosity for HLMU compared to the other two materials is responsible for very low conversion of double bonds. The degree of polymerization is lower for OCDY compared to OCS. This observation is in agreement with a previous study (Swartz et al 1983) and is associated with a higher amount of energy absorbed by surface molecules in the case of the darker shade reducing the amount of penetrating light. This reasoning is further supported by the fact that the average amount of double-bond conversion for different materials is not significantly affected by the irradiation time. The hardness developed after 10 seconds curing for

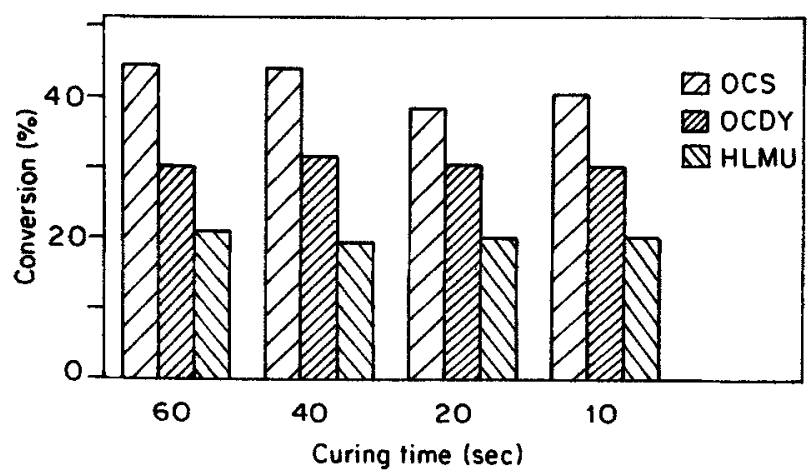

Figure 8. Double bond conversion. Distance: $0-1 \mathrm{~mm}$ from curing surface. 


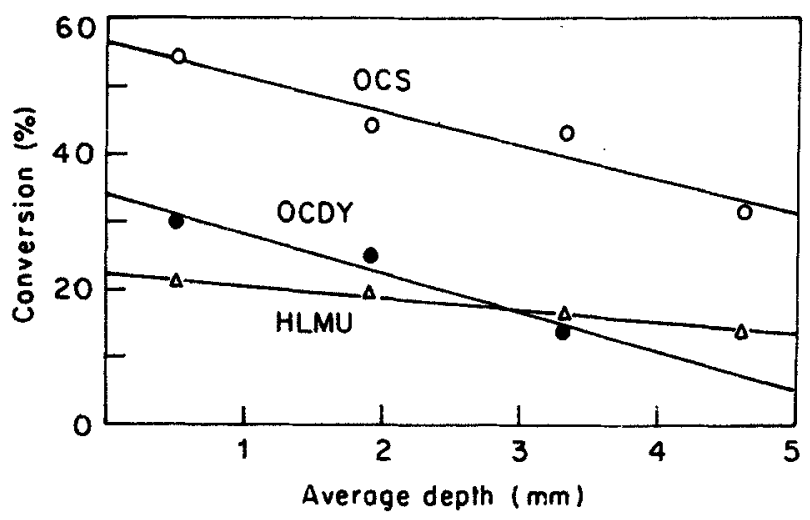

Figure 9. Conversion of double bonds for different materials. Cure time: $60 \mathrm{~s}$.

OCS is more than that of OCDY cured for 60 seconds. This indicates that increased cure time is not an alternative to an adequate level of intensity of light.

Hardness values (figure 7), however, do show an increase in hardness for each material with curing time, although the increase is not significant for HLMU. The possible reason for this behaviour for HLMU is again higher viscosity. A comparison of hardness values at $0.5 \mathrm{~mm}$ depth (figure 7) and average degree of conversion between 0 and $1 \mathrm{~mm}$ depth (figure 8 ) for Occlusin grades for different curing times would suggest that microhardness measurement is a very sensitive test method. The relative insensitivity of the double-bond conversion measured by FTIR techniques could also be due to the fact that the light beam falling on the samples at the time of recording of spectra helps in further polymerization. This results in reducing the difference in the degree of polymerization for samples exposed to visible light for $10-60$ seconds. However, this technique is sensitive enough to differentiate in the double-bond conversion between different grades and shades of materials.

From figure 9 it is observed that the percentage double bond conversion decreases with increasing depth from the curing surface. This is expected because the intensity of light is reduced due to absorption and other losses as depth increases.

The reductions in microhardness and double-bond conversion with distance from the curing surface increases are tabulated in tables 2 and 3. These values have been arrived at by linear regression of the hardness and double-bond conversion data at different depths from the curing surface. Regressed data are in good agreement with experimental values, as can be seen from figures 6 and 9 and predictions can be made about the degree of cure at different depths with a reasonable degree of accuracy.

From table 2 it is observed that reduction in microhardness generally decreases with decrease in cure time. Curing is influenced by the intensity of light and curing time, as well as the material and environmental characteristics. For the same material and environment the intensity of light reaching a particular depth should be the same and the curing time alone should determine the setting characteristics. Intensity of light decreases as the distance from the light source increases. Therefore the layer of the material nearer the light source receives light with higher intensity 
Table 2. Reduction in micro hardness $\left(\mathrm{kg} \mathrm{mm}^{-2}\right) / \mathrm{mm}$.

\begin{tabular}{lccc}
\hline & \multicolumn{3}{c}{ Curing time, (s) } \\
\cline { 2 - 4 } Material code & 60 & 40 & \multicolumn{1}{c}{20} \\
\hline OCS & 17.66 & 14.24 & 9.99 \\
OCLG & 20.55 & 20.17 & 15.19 \\
HLMU & 7.96 & 7.66 & 5.53 \\
\hline
\end{tabular}

Table 3. Reduction in double bond conversion $(\% / \mathrm{mm})$.

\begin{tabular}{lccc}
\hline & \multicolumn{3}{c}{ Curing time, (s) } \\
\cline { 2 - 4 } Material code & 60 & 40 & 20 \\
\hline OCS & 2.80 & 0.35 & 4.42 \\
OCDY & 5.81 & & 4.64 \\
HLMU & 1.82 & 1.49 & 2.65 \\
\hline
\end{tabular}

than the layer farther from the light source. Accordingly, polymerization is greater for a layer near the light source. This difference in the degree of polymerization is further increased with increase in curing time.

Values for the reduction in double bond conversion/mm are very low and are similar for all three materials and curing times (figure 3). Low values indicate that the differences in amount of double-bond conversion at different depths are also low. This was not expected and could be due to the polymerization that might have taken place due to the incident light beam on the samples at the time of recording the spectra.'

From the results it is apparent that when measured immediately after curing a direct correlation of microhardness values with that of double-bond conversion estimated by FTIR technique is not possible even for the same material (having the same formulation variables). The microhardness technique is more sensitive and reliable in such a situation. Aged samples may give better results in the FTIR technique as claimed in an earlier study due to their higher degree of polymerization and hence very little change of degree of polymerization, if at all, takes place during recording of spectra (Dewald and Ferracane 1987).

\section{Acknowledgements}

This work was carried out at the University of Liverpool during the visit of Dr S N Pal under the Indo-UK link programme. Financial and other logistic support of the British Council, the Sree Chitra Tirunal Institute for Medical Sciences and Technology and the University of Liverpool are gratefully acknowledged.

\section{References}

Abdalla M A, Ashrafi S H, Bapna M S and Punwani I 1985 Dent. Mater. 114

Asmussen E 1982 Scand. J. Dent. Res. 90484 
Dewald F and Ferracane J C 1987 J. Dent. Res. 66727

Ferracane J L and Greener E H 1984 J. Dent. Res. 631093

Ferracane J L, Moser J B and Greener E H 1983 IADR Prog. Abstr. 62 No. 3

Ferracane J L, Newman S and Greener E H 1982 IADR Prog. Abstr. 62 No. 8332

Heigl J J, Bell M F and White J N 1947 Anal. Chem. 19293

Newman W M, Murray G A and Yates J L 1983 J. Prosthet. Dent. 5031

Qnose H, Sano H, Kanto H, Ando S and Hasuike T 1985 Dent. Mater. 148

Pollack B F and Blitzer M H 1982 NYS Dent. J. 4228

Reinhardt J W, Denehy G E, Jordon R D and Rittman B R J 1982 Oper. Dent. 7.82

Ruyter I E and Oysaile H 1981 Scan. J. Dent. Res. 6179

Ruyter I E and Peter-Paul Gyrorosi 1976 Scand. J. Dent. Res. 84396

Ruyter I E and Svendsen S A 1978 Acta Odontol. Scan. 3675

Swartz M L, Phillips R W and Rhodes B 1983 JADA 106634

Tirtha R, Fan P L, Dennison J B and Powers J M 1982 J. Dent. Res. 611184

Watts D C, Amer O M and Combe F C 1987 Dent. Mater. 3265

Wu W 1983 IADR Prog. Abstr. 62 No. 192 